\title{
Interlabial Escape; No Progression to Anterior Lip
}

National Cancer Institute

\section{Source}

National Cancer Institute. Interlabial Escape; No Progression to Anterior Lip. NCI

Thesaurus. Code C127184.

A finding of interlabial escape during swallowing, but no progression to anterior lip. 